\title{
Wettability Effects on Capillary Pressure, Relative Permeability, and Irredcucible Saturation Using Porous Plate
}

\author{
Olugbenga Falode and Edo Manuel \\ Department of Petroleum Engineering, University of Ibadan, Ibadan 200284, Nigeria \\ Correspondence should be addressed to Olugbenga Falode; falodelias@yahoo.com
}

Received 24 February 2014; Revised 19 June 2014; Accepted 20 June 2014; Published 17 August 2014

Academic Editor: Chih-Ming Kao

Copyright ( 2014 O. Falode and E. Manuel. This is an open access article distributed under the Creative Commons Attribution License, which permits unrestricted use, distribution, and reproduction in any medium, provided the original work is properly cited.

An understanding of the mechanisms by which oil is displaced from porous media requires the knowledge of the role of wettability and capillary forces in the displacement process. The determination of representative capillary pressure $\left(P_{c}\right)$ data and wettability index of a reservoir rock is needed for the prediction of the fluids distribution in the reservoir: the initial water saturation and the volume of reserves. This study shows how wettability alteration of an initially water-wet reservoir rock to oil-wet affects the properties that govern multiphase flow in porous media, that is, capillary pressure, relative permeability, and irreducible saturation. Initial water-wet reservoir core samples with porosities ranging from 23 to $33 \%$, absolute air permeability of 50 to $233 \mathrm{md}$, and initial brine saturation of 63 to $87 \%$ were first tested as water-wet samples under air-brine system. This yielded irreducible wetting phase saturation of 19 to $21 \%$. The samples were later tested after modifying their wettability to oil-wet using a surfactant obtained from glycerophtalic paint; and the results yielded irreducible wetting phase saturation of 25 to $34 \%$. From the results of these experiments, changing the wettability of the samples to oil-wet improved the recovery of the wetting phase.

\section{Introduction}

Wettability refers to the tendency of one fluid to spread on or adhere to a solid surface in the presence of immiscible fluids as shown in Figure 1 [1]. In natural porous media, the wettability varies from point to point depending upon the surface roughness [2], immobile adsorbed liquid layers [3], and the adsorptive properties of the mineral constituents. Anderson reported that coal, graphite, sulfur, talc, talclike silicates, and many sulfides are probably neutrally wet to oil-wet [4]. On the other hand, most common aquifer materials such as quartz, carbonates, and sulfates are strongly water wet.

It is the wettability of the reservoir rock that controls the distribution of oil and water and affects their movement through pore spaces. Understanding wettability in porous media is, by itself, a difficult problem. Controlling it to modify the behavior of reservoir rock presents a more complex problem. Numerous methodologies for studying, measuring, and altering the wettability of reservoir rocks are found in literature. No satisfactory method exists for in situ measurement of wettability, and therefore it is necessary to estimate the wettability of reservoir rocks from laboratory measurements.

It is known that a porous material can be defined as waterwet, oil-wet, or mixed-wet. The degree to which a reservoir is one or another of these can be determined by considering the capillary pressure curve, or by characterizing it in terms of wettability indices.

Several experimental procedures have been proposed to assign quantitative wettability indexes to reservoir rock surfaces. The most recent of these proposals are those of Morrow [5], Graue et al. [6], and Derahman and Zahoor [7]. These indexes are designed to show a continuous variation from the preferential oil-wet to the preferential water-wet systems. They require measuring some property of the rock which is a function of surface wettability. The quantities are measured on unaltered core material and compared with values obtained for known oil-wet and water-wet extremes on the same material. These methods are useful but are 


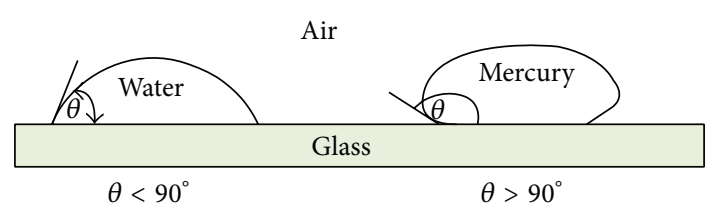

FIGURE 1: Wetting fluid (water) and nonwetting fluid (mercury).

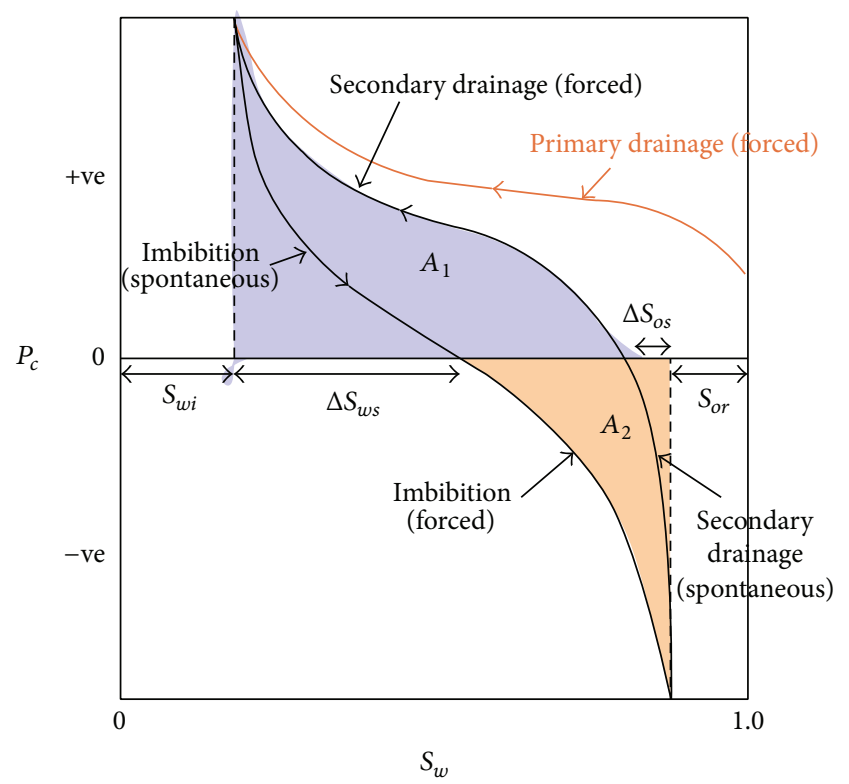

FIGURE 2: Capillary pressure diagram used to characterize wettability.

semiempirical in nature. They have the disadvantage that the measured quantities may be functions of other variables in addition to surface wettability.

(a) Amott Indices. Referring to Figure 2, the Amott indices are defined as

$$
I_{o}=\frac{\Delta S_{o s}}{1-S_{w i}-S_{o r}}, \quad I_{w}=\frac{\Delta S_{w s}}{1-S_{w i}-S_{o r}} .
$$

If the material is completely water-wet, then $I_{o}=0$ and $I_{w}=$ 1. If the material is strongly oil-wet then $I_{o}=1$ and $I_{w}=0$. $I_{o}$ is the displacement-by-oil ratio and is the water volume displaced by spontaneous oil imbibition, relative to the total water volume displaced by oil imbibition (spontaneous and forced). $I_{w}$ is the displacement-by-water ratio and is the oil volume displaced by spontaneous water imbibition, relative to the total oil volume displaced by water imbibition (spontaneous and forced). For connected pathways of oil and water then both indices can be greater than zero.

(b) USBM Wettability Index. This index is based on the ratio of the two areas representing forced imbibition in Figure 2:

$$
N_{w}=\log \left(\frac{A_{1}}{A_{2}}\right) .
$$

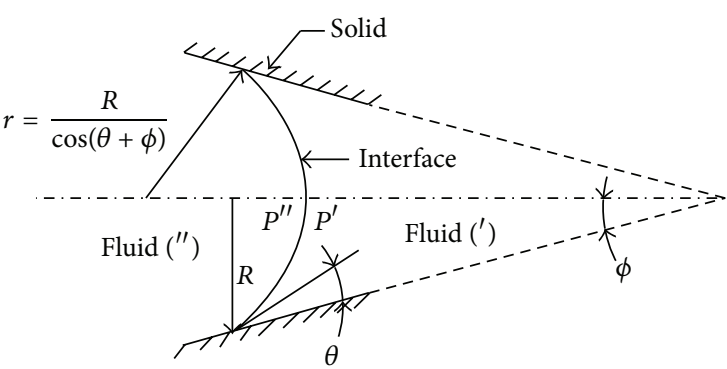

Figure 3: Fluid interface in a tapered capillary tube.

The range is from $+\infty$ for a completely water-wet material to $-\infty$ for a completely oil-wet material. Typical values are in the range of -1.5 to +1.0 . In general this index is not used very much.

In this work, the wettability of the tested samples was not determined. Most common aquifer materials such as quartz, carbonates, and sulfates are strongly water-wet and since the tested samples are quartz and carbonates materials, it was therefore assumed that they are water-wet.

When two immiscible fluids are in contact in the interstices of a porous medium, a discontinuity in pressure exists across the interface separating them. The difference in pressure $\left(P_{c}\right)$ is called capillary pressure. The capillary pressure is dependent on the interfacial tension, pore size, and wetting angle. Capillary pressure is the most fundamental rock/fluid property in multiphase flow, just as porosity and permeability are for single phase flow in oil and gas reservoirs [8]. Capillary pressure curves directly determine the irreducible water saturation, residual oil saturation, and rock wettability and can be used to determine water oil contact point and approximate oil recovery. Figure 2 is a capillary pressure diagram showing how it can be used to characterize wettability and the capillary pressure is the difference in pressure $\left(P_{c}\right)$ as exemplified by Figure 3 where the porous medium can be described by a capillary tube where a clear interface exists between the immiscible fluids. Water flood performance is also significantly affected by the capillary pressure of the rock [9].

By definition, the capillary pressure is the nonwetting fluid pressure minus the wetting fluid pressure:

$$
P_{c}=P_{\text {non-wetting }}-P_{\text {wetting }} \text {. }
$$

The capillary pressure $P_{c}$ can be calculated by the Laplace equation:

$$
P_{c}=\sigma\left(\frac{1}{r_{1}}+\frac{1}{r_{2}}\right) .
$$

The capillary pressure equation can be expressed in terms of the surface and interfacial tension by

$$
P_{c}=\frac{2 \sigma \cos \theta}{r},
$$

where $\sigma$ is interfacial tension between the two fluids and $r_{1}$ and $r_{2}$ are principle radii of curvature and $\theta$ is the 


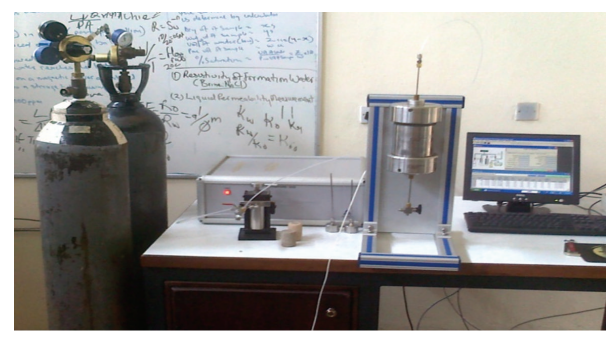

FIGURE 4: ULTRAPORE-300 assembly.

contact angle. Capillary pressure data are not only important for obtaining reservoir rock properties such as pore size distribution, permeability, and water saturation profile within the oil reservoir but also provide important information for water flooding designs and reservoir simulation studies.

Capillary pressure is typically measured in the laboratory by mercury injection, porous plate, or centrifugation techniques. The porous plate method (PP) has been used for years in acquiring reliable capillary pressure data representative of reservoir rock fluid properties. In recent years, the method is also found to be reliable and subject to less experimental errors and analysis when used for electrical resistivity (RI) measurements as well. A major problem has been the long time scales required for achieving reliable data.

The mercury injection technique is fast and can reach very high capillary pressure but the test uses nonrepresentative fluid, mercury and it is destructive, whereas the centrifugation technique [10] uses reservoir fluids and decreases the equilibrium time by using high centrifugal forces.

In this study, the porous plate method was used in acquiring the capillary pressure data of the tested samples.

The term relative permeability refers to the phase permeability relative to the absolute permeability $k$ :

$$
k_{r o}=\frac{k_{o}}{k}, \quad k_{r w}=\frac{k_{w}}{k}, \quad k_{r g}=\frac{k_{g}}{k} \text {. }
$$

Several mathematical models have been proposed to infer relative permeability from capillary pressure data. In 2008, Derahman and Zahoor demonstrated a method of calculating the permeability using capillary pressure curves measured by mercury injection [7]. A tortuosity factor in the model was earlier introduced and the method was modified by representing capillary pressure curve as a power law function of the wetting phase saturation [11-13]. As mentioned previously, capillary pressure and relative permeability are both measured in the laboratory; however, it is time consuming and expensive to both in many cases. For the purpose of this study, the empirical Brooks-Corey-Burdine formulae [11-13] are used:

$$
\begin{aligned}
k_{r w} & =s_{e w}^{4}, \\
k_{r n w} & =\left(1-s_{e w}\right)^{2}\left(1-s_{e w}^{2}\right), \\
s_{e w} & =\frac{s_{w}-s_{r w}}{1-s_{r w}},
\end{aligned}
$$

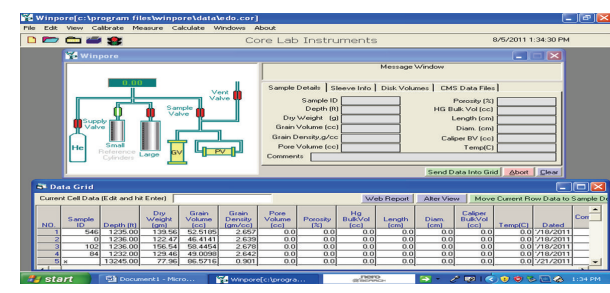

FIGURE 5: WINPORE snapshot.

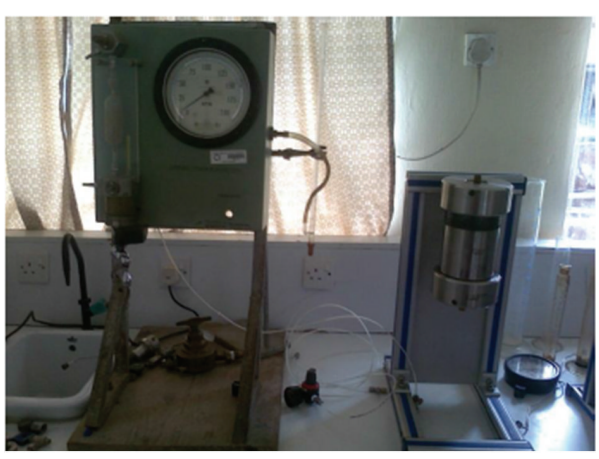

FIGURE 6: Frank Jones liquid permeameter.

where $K_{r w}$ and $K_{r n w}$ are the wetting phase and nonwetting phase relative permeability, respectively; $S_{e w}, S_{r w}$, and $S_{w}$ are the effective wetting phase saturation, wetting phase residual saturation, and wetting phase saturation, respectively.

\section{Justification for This Study}

Several studies have been conducted on wettability reversal effects on oil recovery using different surfactants to deliberately improve oil recovery; however, the literature is sparse on wettability alteration that results from contact with the components of corrosion inhibitors or paints; the focus of this study. Moreover, no study of such has been reported on the Niger Delta formations.

\section{Brief Literature Cited}

Sayari and Blunt [14] performed benchmark experiments on multiphase flow in which they investigated the effect of wettability on relative permeability, capillary pressure, electrical resistivity, and nuclear magnetic resonance (NMR). In that study, they compared the results obtained from a suite of experimental measurements on well characterized systems that studies relevant properties such as capillary pressure, relative permeability, NMR response, and resistivity index with numerical predictions using pore-scale modeling where the pore space was imaged with micro-CT scanning.

Al-Garni and Al-Anazi [15] correlated the wettability, capillary pressure, and initial fluids saturation for Saudi Arabia crude oil. In their study, they correlated irreducible oil saturation and capillary pressures using rock centrifuge measurements for Berea rock Sandstone samples on Saudi crude oils during drainage and imbibition cycles by varying 


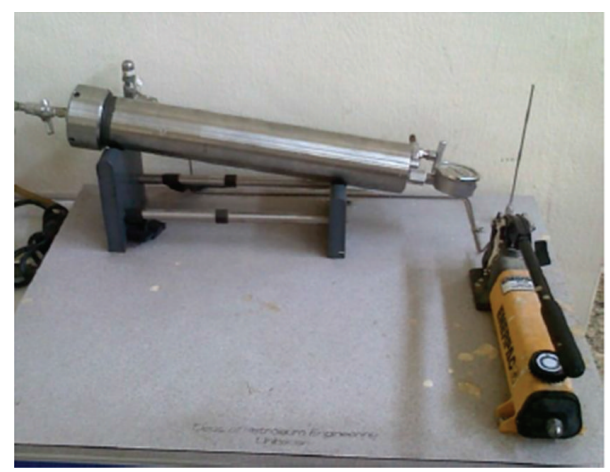

FIgURE 7: Saturator.

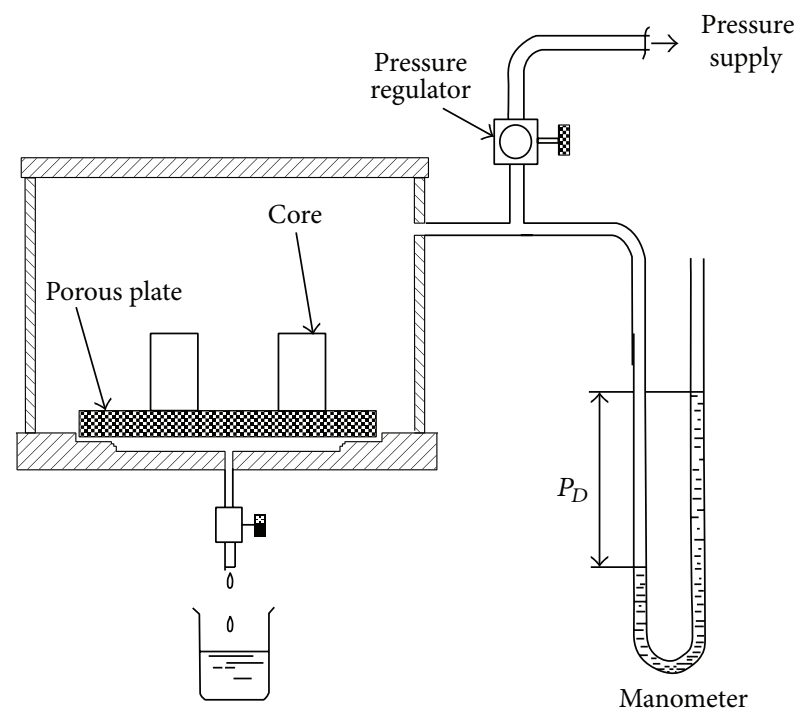

Figure 8: Porous plate diagram.

each time the wettability of the tested samples using different Saudi oils (heavy, medium, and light).

Green et al. [16] presented a new method of determining the capillary pressure by direct measurement of the saturation using magnetic resonance imaging (MRI). He used the Hassler and Brunner equation at each radial position in the rock to calculate the capillary pressure, which together with saturation measured with MRI at each position directly produces a capillary pressure curve with as few as single centrifuge equilibrium [10]. The technique is reported to be rapid, accurate and ideally suited to study "tight" or low permeability rocks.

Chen et al. [17] discussed on NMR wettability indices: effect of OBM on wettability and NMR responses. The findings of that study were that cationic surfactant dodecylamine alters the wettability of glass slide surface while anionic surfactant; stearic acid alters the wettability of marble surface. They were able to correlate the proposed NMR wettability indices (water index, oil index, or combined index) with the traditional Amott-Harvey indices, suggesting that quantitative information about rock wettability can be gained from NMR measurements.

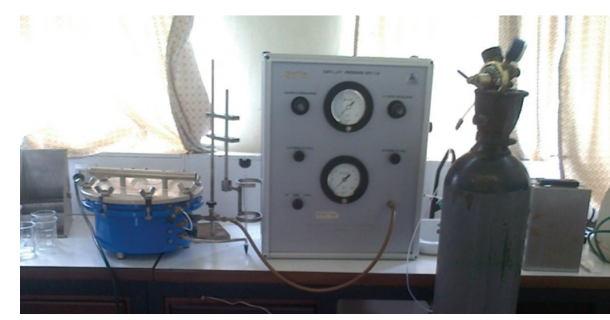

FIGURE 9: Ceramic plate/capillary pressure cell.

O'Carroll et al. [18] in their study predicted two-phase capillary pressure/saturation relationships in fractional wettability systems. They presented a new two-phase capillary pressure/saturation model for application to the prediction of primary drainage and imbibition relations in fractional wettability media. That new model was based on extension of Leverett scaling theory.

Békri et al [19] studied the effect of wettability on the petrophysical parameters of vuggy carbonates. In their study, they modelled a dual network for dual porosity rocks which satisfactorily reproduced the capillary pressure curve, the porosity, and the permeability determined experimentally on a double porosity rock. They found that the contrast between primary and secondary pore space characteristics has a major effect on both the capillary pressure and the relative permeabilities.

Li and Firoozabadi [20] showed that if the wettability of porous media can be altered from preferential liquid wetting to preferential gas-wetting, then gas well deliverability in gas condensate reservoirs can be increased.

Hui and Blunt [21] studied the effects of rock wettability on the flow of oil, water, and gas in hydrocarbon reservoirs. They described the three-phase fluid configurations and displacement processes in a pore of polygonal cross section.

\section{Methodology}

The present work relies on laboratory experimental results obtained from routine and special core analysis. In conducting the routine core analysis, properties such as porosity, permeability, and the percentage saturation of the tested sample were determined, while only the capillary pressure data of the tested samples were determined during the special core analysis. In this section, we describe the experimental procedures that were used in determining the above rock properties.

\subsection{Routine Core Analysis}

4.1.1. Porosity. In this study, the ULTRAPORE-300 as shown in Figure 4 was used to estimate the absolute porosity of the four (04) tested samples. The porosity of a rock is mathematically defined as

$$
\phi=\frac{\text { pore volume }}{\text { bulk volume }} * 100(\%) .
$$




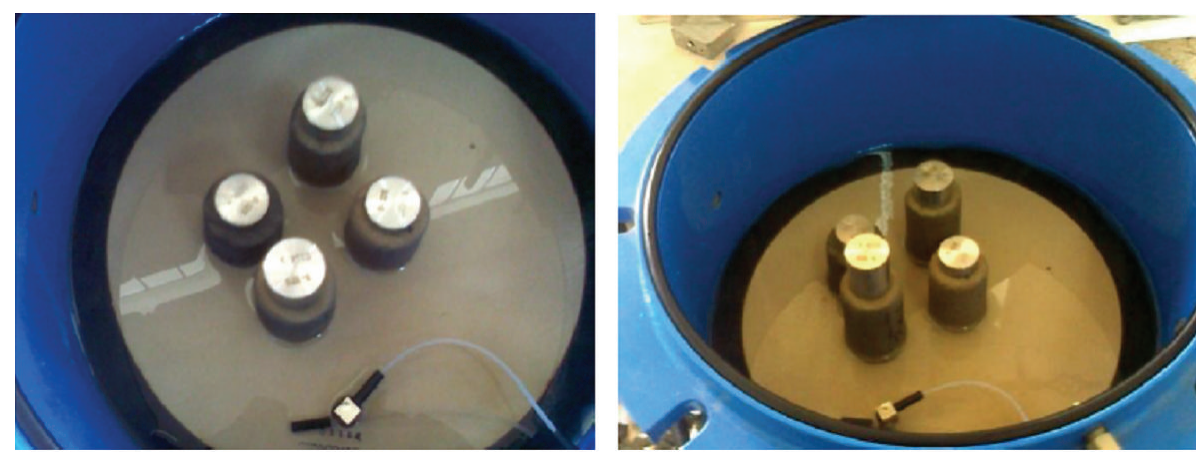

Figure 10: Water-wet samples loaded into ceramic plate.

In this study, the ULTRAPORE-300 was used to estimate the absolute porosity of the four (04) tested samples. The ULTRAPORE-300 system software (WINPORE) computed the grain volume, pore volume, and the grain density of the samples. The testing procedure used in determining the grain volume and pore volume is as follows.

\subsubsection{Grain Volume Determination}

(i) The samples were dried and weighted after which they were loaded one after the other inside a $11 / 2^{\prime \prime}$ diameter matrix cup.

(ii) The ULTRAPORE-300 system software (WINPORE) was first calibrated to obtain a reference volume for grain volume measurement.

(iii) Nitrogen gas was allowed to flow into the $11 / 2^{\prime \prime}$ diameter matrix cup system at a pressure $P$ (psi).

(iv) The system generated a set of corresponding volume at that pressure $P$ for each sample loaded and used the Boyle's law equation in computing the samples grain volume.

\subsubsection{Pore Volume Determination}

(i) The pore volume of the samples was determined similarly as the grain volume except that the system software was calibrated for pore volume instead of grain volume.

(ii) The samples were then loaded into a rubber boot placed inside a hydrostatic core holder at an overburden pressure of 200 psi where the nitrogen gas was allowed to flow in the core holder to fill the pore spaces of the samples at equilibrium.

(iii) The system software (WINPORE) generated then the pore volume of the samples (Figure 5). The grain density of each sample was computed by the system software. The bulk volume of the samples was computed empirically.

4.1.4. Air Permeability Determination. The testing procedure used is as follows. (i) The samples were loaded inside a core holder connected to the gas permeameter (Figure 6).

(ii) Nitrogen gas was allowed to flow into the samples using a regulator to obtain a laminar flow regime. The laminagr flow regime was determined using a bubble flow meter to ascertain that the flow rate does not exceed $1 \mathrm{cc} / \mathrm{s}$.

(iii) Using the bubble-tool flow meter, the flow rate at which the gas flow through the samples was determined using the flow rate definition.

(iv) The air permeability was then computed from the equation given below:

$$
k=\frac{2000 P_{b} * Q * \mu *(l / A)}{\left(P+P_{b}\right)^{2}-P_{b}^{2}},
$$

where $P_{b}$ is barometric pressure (atm), $\mu$ is $N_{2}$ viscosity, (cp), $P$ is measured pressure (atm), $l$ is sample length, $(\mathrm{cm}), Q$ is flow rate, $(\mathrm{cc} / \mathrm{s})$, and $A$ is sample area, $\left(\mathrm{cm}^{2}\right)$.

4.1.5. Percentage Saturation Determination. This property is expressed mathematically by the following relationship:

$$
\text { fluid saturation }=\frac{\text { total volume of fluid }}{\text { pore volume }} * 100(\%) \text {. }
$$

Saturation is a direct measure of the fluid content of the porous rock. It therefore directly influences the hydrocarbon storage capacity of the reservoir.

In the pores of oil or gas reservoirs, there always remains some water that was there before the hydrocarbon entrapment. At any time during the life of an oil or gas reservoir, the following relationship must hold true:

$$
\begin{gathered}
S_{o}+S_{w}+S_{g}=1.0, \\
S_{o}=\frac{\text { oil volume }}{\text { pore volume }}=\frac{V_{o}}{V_{p}}, \\
S_{w}=\frac{\text { water volume }}{\text { pore volume }}=\frac{V_{w}}{V_{p}}, \\
S_{g}=\frac{\text { gas volume }}{\text { pore volume }}=\frac{V_{g}}{V_{p}} .
\end{gathered}
$$



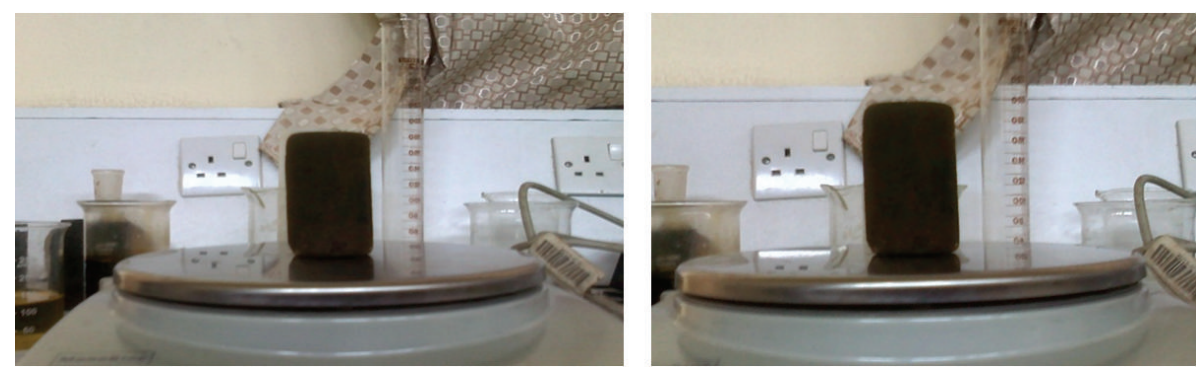

(a) Weighing saturated water-wet sample before wettability alteration $\left(S_{\text {unmod }}\right)$
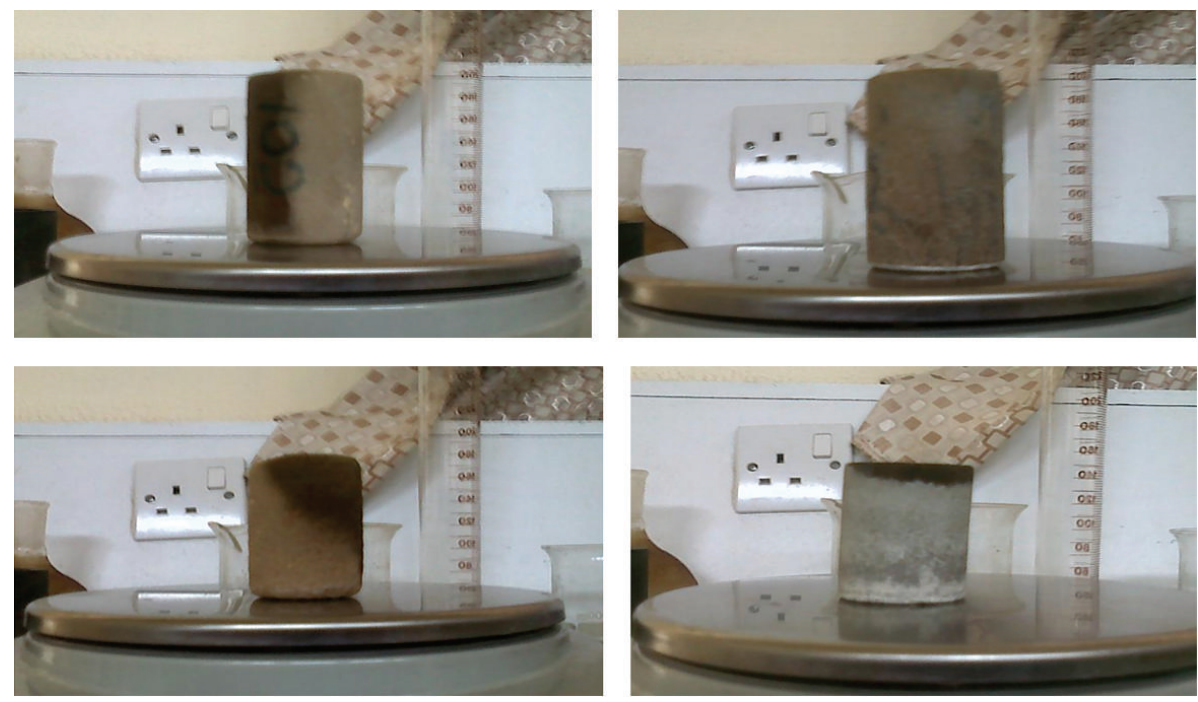

(b) Weighing saturated (light oil) after wettability alteration to oil-wet $\left(S_{\text {mod }}\right)$

FIGURE 11

TABLE 1: Routine core analysis results.

\begin{tabular}{lccccccccc}
\hline Core & $\begin{array}{c}L \\
(\mathrm{~cm})\end{array}$ & $\begin{array}{c}D \\
(\mathrm{~cm})\end{array}$ & $\begin{array}{c}\mathrm{BV} \\
(\mathrm{cc})\end{array}$ & $\begin{array}{c}\mathrm{GV} \\
(\mathrm{cc})\end{array}$ & $\begin{array}{c}\text { GD } \\
(\mathrm{g} / \mathrm{cc})\end{array}$ & $\begin{array}{c}\text { Porosity } \\
(\%)\end{array}$ & $\begin{array}{c}S_{w i} \\
(\%)\end{array}$ & $\begin{array}{c}S_{o i} \\
(\%)\end{array}$ & $\begin{array}{c}K_{a} \\
(\mathrm{md})\end{array}$ \\
\hline 102 & 7.16 & 3.86 & 84.16 & 25.72 & 2.68 & 30.56 & 62.79 & 70.88 & 139 \\
546 & 6.81 & 3.83 & 78.59 & 52.51 & 2.65 & 33.18 & 71.98 & 64.58 & 231 \\
84 & 6.25 & 3.78 & 70.23 & 49.02 & 2.64 & 30.20 & 59.41 & 58.75 & 223 \\
$\mathrm{X}$ & 5.13 & 3.88 & 60.90 & 46.41 & 2.69 & 23.79 & 87.31 & 86.27 \\
\hline
\end{tabular}
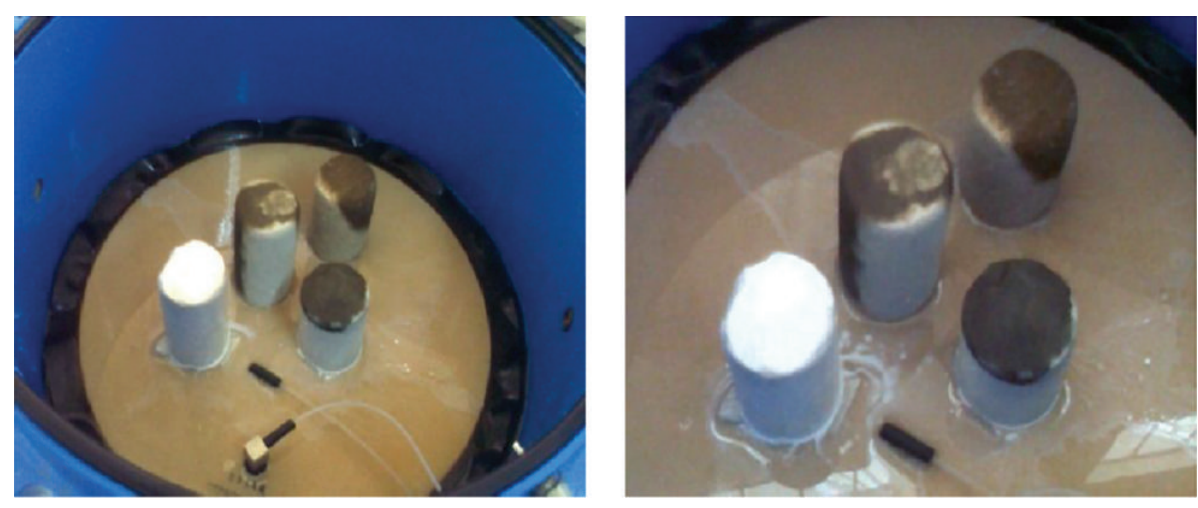

FIGURE 12: Samples loaded into the ceramic plate after wettability alteration to oil-wet. 


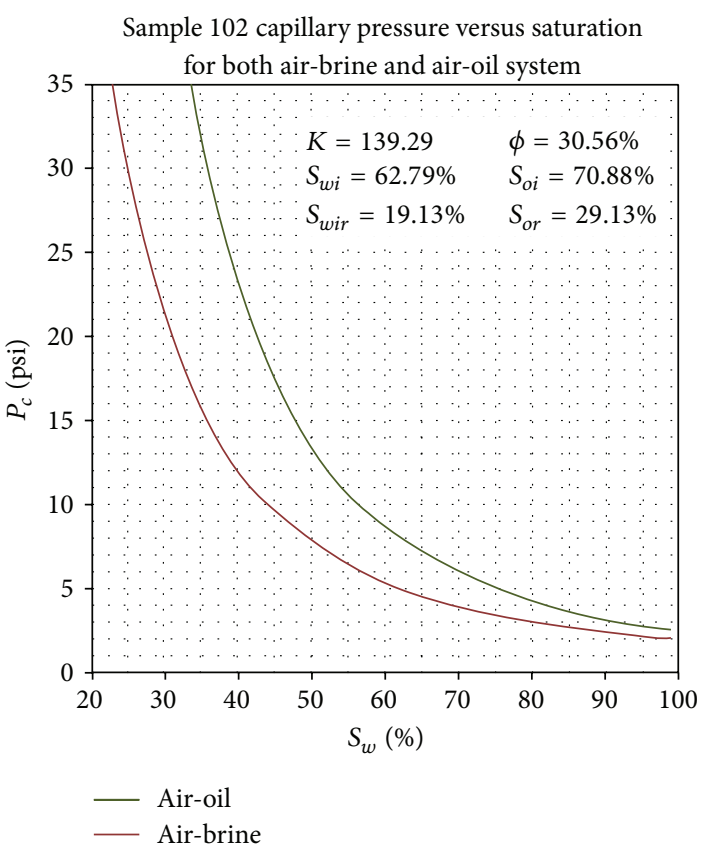

(a)

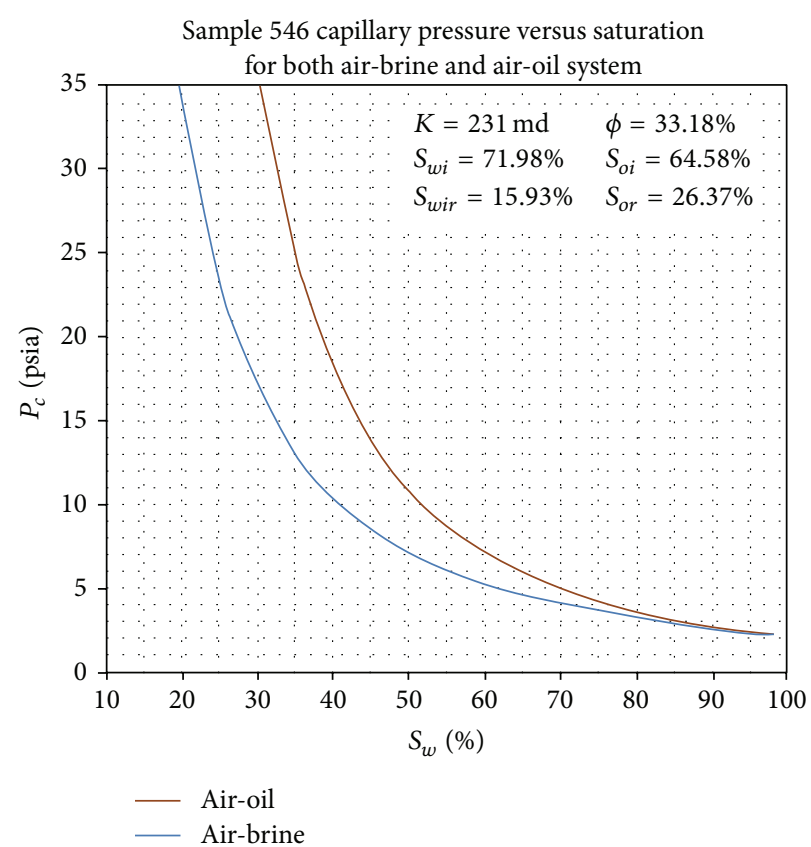

(b)

FIGURE 13: $P_{c}$ versus $S_{w}$ (air-brine) $)_{S_{\text {unmod }}}$ and (air-oil system $)_{S_{\text {mod }}}$. Capillary pressure $\left(P_{c}\right)$ versus Saturation $\left(S_{w}\right)$ curves.

It is common for oil or gas saturation to be zero, but water saturation is always greater than zero.

The percentage saturation of the tested samples was measured as follow:

(i) The dry weight of the samples was recorded.

(ii) The samples were loaded in the saturator and air was evacuated from the saturator for 30 minutes using vacuum pump.

(iii) The saturator was filled with the saturating fluid (brine or light oil) at a pressure of 1000 psi for 24 hours, after which the samples were removed from the saturator and their net weight were recorded (Figure 7).

4.2. Special Core Analysis. For the purpose of this work, only the capillary pressure of the tested samples was determined from the special core analysis. The porous plate method was used for that purpose. In doing so, a set of capillary pressure data was acquired under different wettability conditions. The first set of capillary pressure data was acquired for water-wet core sample, while the second set of capillary pressure data was acquired after the wettability of the samples was altered to oil wet by smearing paint (alkyd resins) on the surface of the tested samples.

\subsubsection{Capillary Pressure Measurement Using the Porous Plate Method}

Testing Procedure. The semipermeable porous plate was first prepared (Figure 8). Plates for oil and brine were separated.
The plates were first saturated with distilled water or light mineral oil and then tested for leaks.

Once saturated, the plate was not allowed to dry because fractures will often occur. Before use, the plate was flushed with the brine or oil that the samples are saturated with. This was accomplished in the cell by pouring some of the liquid into the cell (Figure 9). Cover the plate with $1 / 2^{\prime \prime}$ of liquid. Close the cell and apply a 35 psi air pressure. Pressure is generally provided by a pressure gauge control panel which has gauges ranging in pressure from 1 psi to 50 psi.

Once the plate has been prepared and the samples saturated, they are now loaded into the cell. Place a disc of white clean tissue paper on one end face of the sample to prevent possible contamination and damage to the wettability characteristics of the samples. The disc should be of the same diameter as the core sample. The tissue will ensure that good capillary contact is made. Once the samples are in place in the cell (Figure 10), clean the o-rings on the top and bottom of the barrel. Carefully lower the barrel on the porous plate and samples and align it to the base. Gently place the lid on the barrel; insert the screw that holds it in place and do not overtighten.

Connect the air pressure source to the valve on the lid. Preset the regulator and gauge to the first pressure (1 psi); gently open the valve leading from the pressure panel and listen for the sound of air flowing into the cell. Close the exhaust valve. Put the drain line into a small beaker partially filled with water and open the valve in the base of the cell. The pressures used routinely in air-brine system are 1, 2, 5, 8,15 , and 35 psi. Pressure is maintained until equilibrium is reached. This is determined by weighing the samples on successive days until the weights of all the samples are constant. 


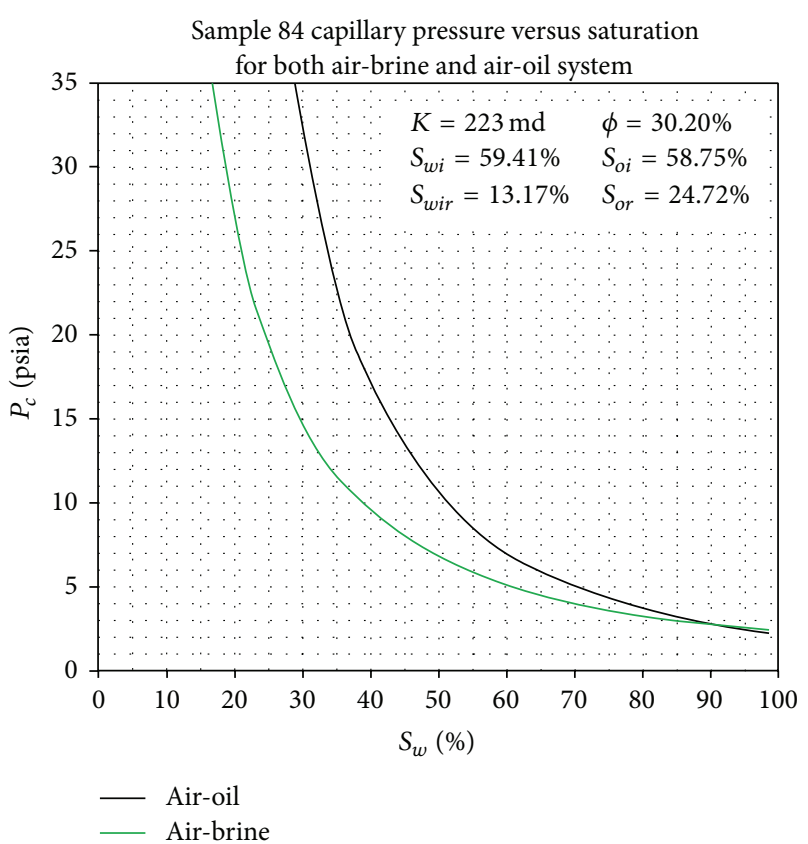

(a)

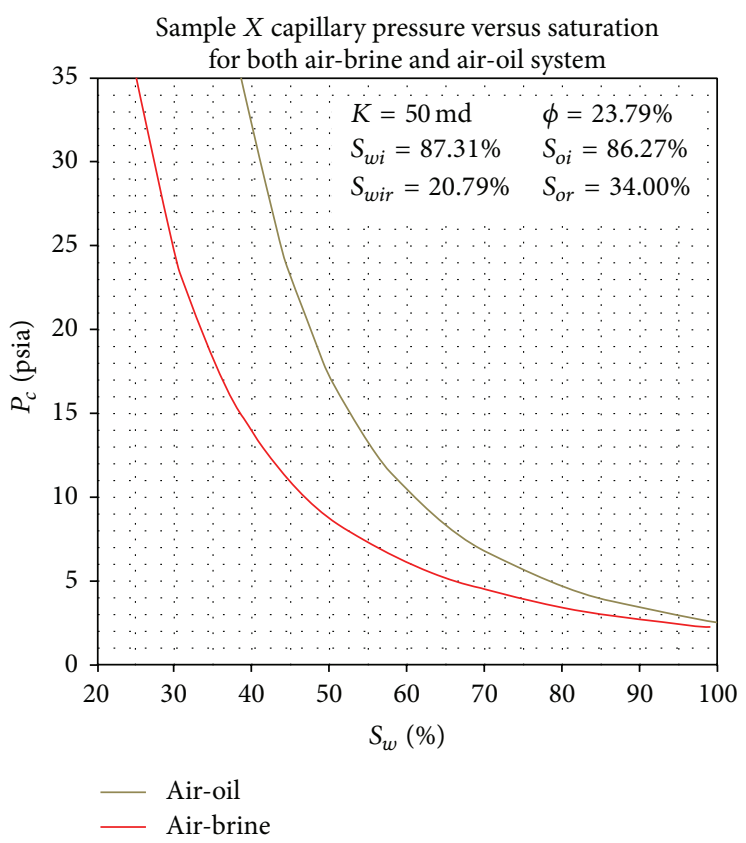

(b)

FIGURE 14: $P_{c}$ versus $S_{w}$ (air-brine) $)_{S_{\text {unmod }}}$ and (air-oil system) $S_{S_{\text {mod }}}$.

TABLE 2: Air-brine capillary pressures and saturations of the samples $\left(S_{\text {unmod }}\right)$.

\begin{tabular}{lcccc}
\hline$P_{c}$ (psi) & $\begin{array}{c}S_{W}(\%) \\
\text { Sample 102 }\end{array}$ & $\begin{array}{c}S_{W}(\%) \\
\text { Sample 546 }\end{array}$ & $\begin{array}{c}S_{W}(\%) \\
\text { Sample 84 }\end{array}$ & $\begin{array}{c}S_{W}(\%) \\
\text { Sample X }\end{array}$ \\
\hline 1 & 98.39 & 98.24 & 98.25 & 99.05 \\
2 & 90.90 & 91.85 & 91.19 & 91.94 \\
5 & 80.06 & 80.02 & 82.06 & 82.61 \\
8 & 62.72 & 63.19 & 65.71 & 67.19 \\
15 & 43.22 & 41.77 & 42.54 & 48.77 \\
35 & 19.13 & 15.93 & 13.17 & 20.79 \\
\hline
\end{tabular}

TABLE 3: Air-oil capillary pressures and saturations of the samples $\left(S_{\text {mod }}\right)$.

\begin{tabular}{lcccc}
\hline$P_{c}(\mathrm{psi})$ & $\begin{array}{c}S_{o}(\%) \\
\text { Sample 102 }\end{array}$ & $\begin{array}{c}S_{o}(\%) \\
\text { Sample 546 }\end{array}$ & $\begin{array}{c}S_{o}(\%) \\
\text { Sample 84 }\end{array}$ & $\begin{array}{c}S_{o}(\%) \\
\text { Sample X }\end{array}$ \\
\hline 1 & 98.90 & 98.22 & 98.56 & 100 \\
2 & 96.16 & 93.65 & 94.94 & 98.40 \\
5 & 90.51 & 85.57 & 86.76 & 90.64 \\
8 & 81.24 & 71.85 & 70.95 & 81.36 \\
15 & 60.45 & 50.24 & 51.61 & 62.72 \\
35 & 29.13 & 26.37 & 24.72 & 34.00 \\
\hline
\end{tabular}

To open the cell, close the drain valve and the pressure valve. Slowly open the exhaust valve and once the pressure has been vented, the cell can be safely opened. The test is complete once the weights have been obtained at equilibrium for the last pressure setting. After the test is complete, the porous plate must be cleaned and prepared for storage or reuse.

The testing procedure described above was used for airbrine system whereby the wettability of the core sample was not altered (water wet samples). Air-oil tests are performed in the same manner as described above except that a low viscosity refined mineral oil such as Isopar was used to saturate the samples and the porous plate. Because air-brine and air-oil systems have different surface tension values, the pressure settings were different and $0.5,1,2,5,8$, and $15 \mathrm{psi}$ were used for air-oil system.

4.2.2. Air-Brine System Capillary Pressure Measurement. In this study, the procedure described above was used for airbrine system in acquiring the capillary pressure data of the core samples.

4.2.3. Air-Oil System Capillary Pressure Measurement. Airoil tests are performed in the same manner as for the airbrine system except that the samples and the porous plate were saturated with oil and the pressure settings are $0.5,1$, $2,5,8$, and $12 \mathrm{psi}$. In this work, the air-oil system procedure of measuring capillary pressure was as for the air-brine except that the wettability of the core samples was altered to oil-wet.

4.2.4. Wettability Modification. Glycerophtalic paint (SigmaAldrich, Inc.) was dissolved by stirring overnight in acetone at room temperature. Then, the solution was placed in a $60 \mathrm{~cm}^{3}$ syringe with a 20 -gauge blunt tip needle. The tipto-substrate distance was set at $20 \mathrm{~cm}$ and the solution was flowed on the surface of the samples at a rate of $15 \mathrm{~mL} / \mathrm{hr}$ with a syringe pump (KDS100, KD Scientific Inc.) as shown in Figures 11(a) and 11(b). The paint solutions used for wettability modification in the experimental work were $2 \mathrm{~mm}$ thick. Samples were then loaded into the ceramic plate after wettability alteration (Figure 12). Samples whose surfaces 


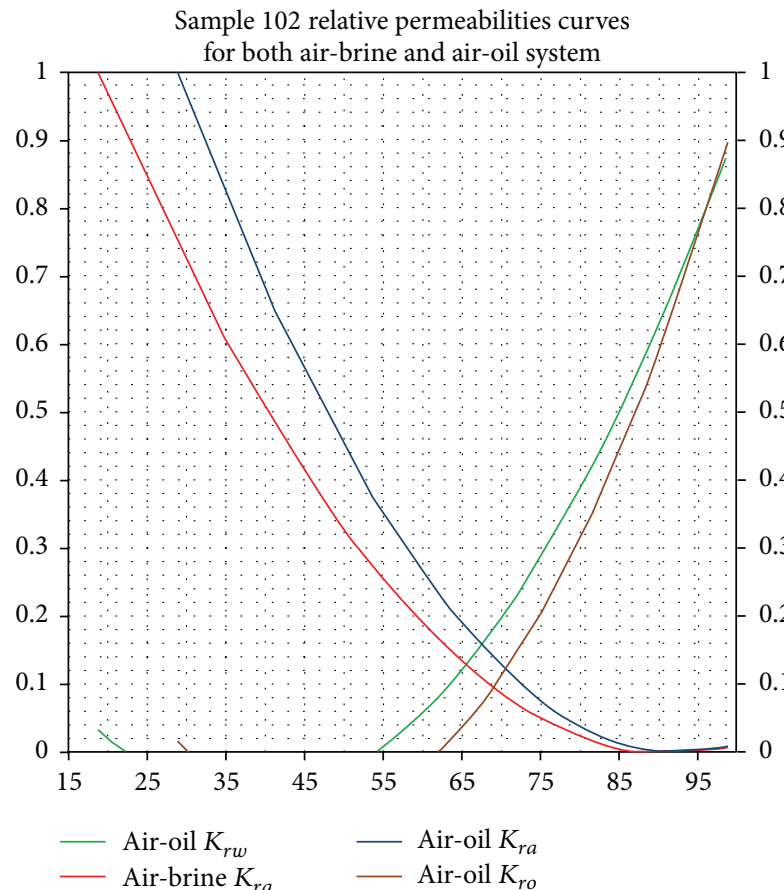

(a)
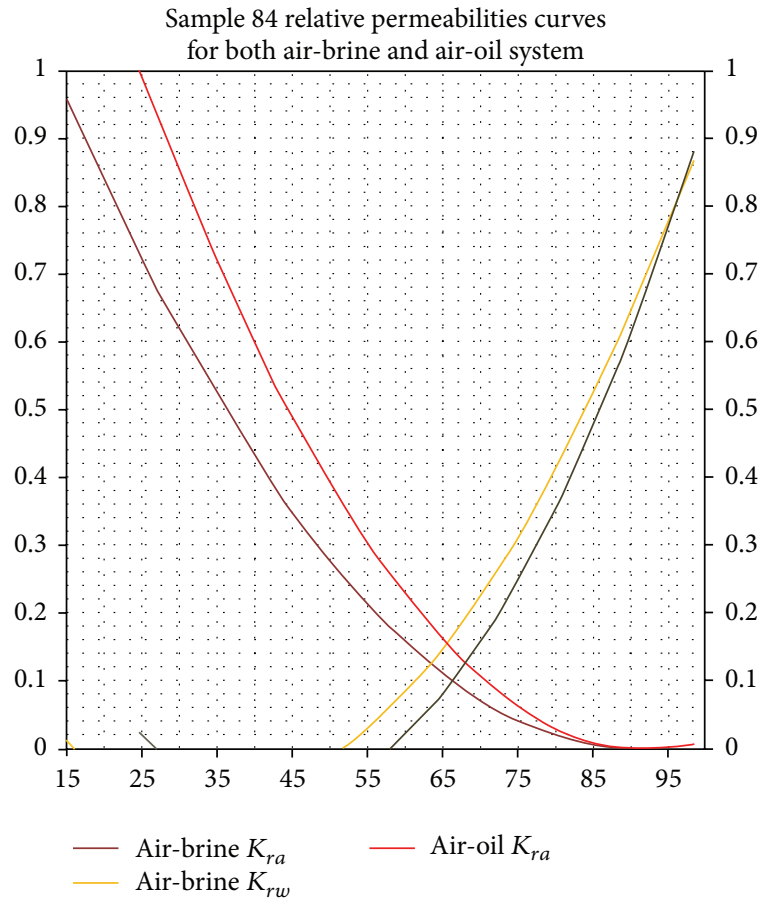

(c)

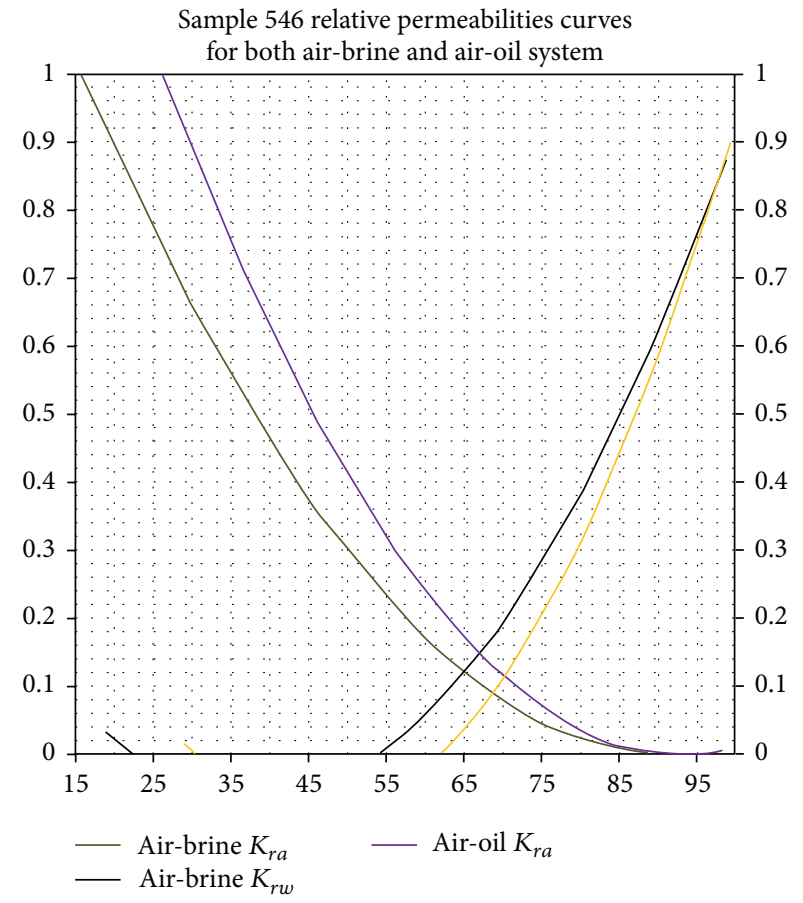

(b)

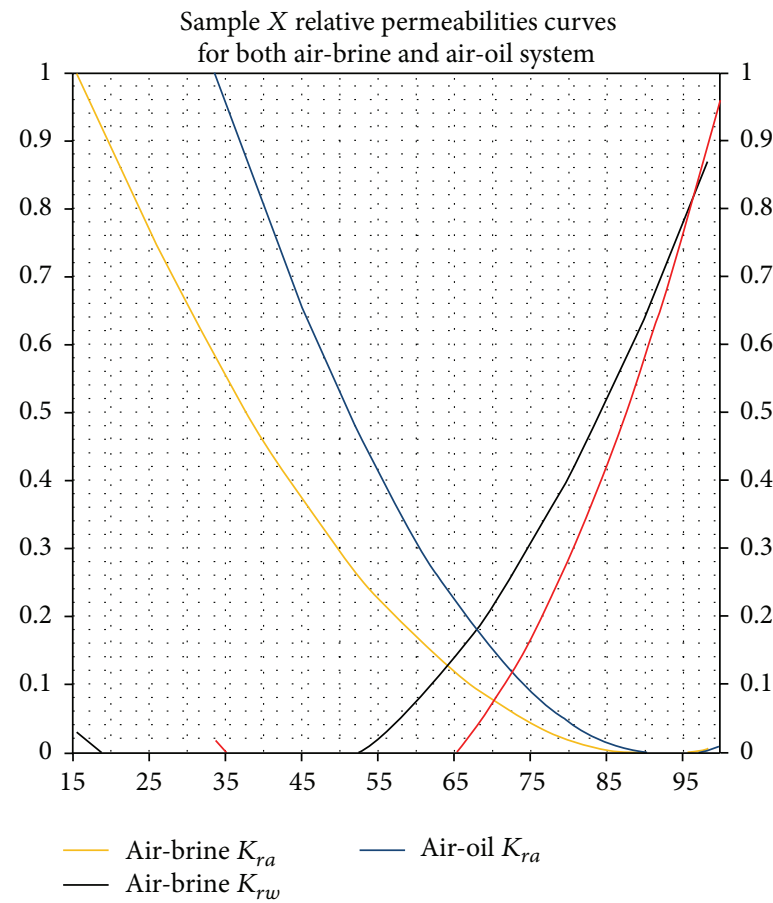

(d)

FIGURE 15: Relative permeability curves for both (air-brine) ${ }_{S_{\text {unmod }}}$ and (air-oil system) ${ }_{S_{\text {mod }}}$. 
TABLE 4: Relative permeability of the core samples $(\text { air-oil system) })_{S_{\text {mod }}}$.

\begin{tabular}{|c|c|c|c|c|c|}
\hline Core & $P_{c}(\mathrm{psi})$ & $S_{o}(\%)$ & $S_{o}{ }^{*}(\%)$ & $K_{r o}$ & $k_{r a}$ \\
\hline \multirow{6}{*}{102} & 1 & 98.90 & 98.45 & 0.94 & 0.00000736 \\
\hline & 2 & 96.16 & 94.58 & 0.80 & 0.000309463 \\
\hline & 5 & 90.51 & 86.61 & 0.56 & 0.004480077 \\
\hline & 8 & 81.24 & 73.53 & 0.29 & 0.032185768 \\
\hline & 15 & 60.45 & 44.20 & 0.04 & 0.250592803 \\
\hline & 35 & 29.13 & 0.00 & 0.00 & 1.00 \\
\hline \multirow{6}{*}{546} & 1 & 98.22 & 97.58 & 0.91 & 0.00002798 \\
\hline & 2 & 93.65 & 91.37 & 0.70 & 0.001229596 \\
\hline & 5 & 85.57 & 80.40 & 0.42 & 0.01357682 \\
\hline & 8 & 71.85 & 61.77 & 0.15 & 0.090360622 \\
\hline & 15 & 50.24 & 32.42 & 0.01 & 0.408713015 \\
\hline & 35 & 26.37 & 0.00 & 0.00 & 1.00 \\
\hline \multirow{6}{*}{84} & 1 & 98.56 & 98.08 & 0.93 & 0.000013998 \\
\hline & 2 & 94.94 & 93.28 & 0.76 & 0.000585609 \\
\hline & 5 & 86.76 & 82.41 & 0.46 & 0.009928657 \\
\hline & 8 & 70.95 & 61.41 & 0.14 & 0.09277698 \\
\hline & 15 & 51.61 & 35.71 & 0.02 & 0.360552895 \\
\hline & 35 & 24.72 & 0.00 & 0.00 & 1.00 \\
\hline \multirow{6}{*}{$\mathrm{X}$} & 1 & 100 & 100 & 1.00 & 0.00 \\
\hline & 2 & 98.40 & 97.58 & 0.91 & 0.000028149 \\
\hline & 5 & 9064 & 85.82 & 0.54 & 0.005300099 \\
\hline & 8 & 81.36 & 71.76 & 0.27 & 0.038692057 \\
\hline & 15 & 62.72 & 43.52 & 0.04 & 0.258638789 \\
\hline & 35 & 34 & 0.00 & 0.00 & 1.00 \\
\hline
\end{tabular}

$\left(S_{o}{ }^{*}\right.$ is the effective oil saturation).

were modified were labeled $S_{\text {mod }}$ while normal samples were labeled $S_{\text {unmod }}$.

\section{Results and Discussion}

\subsection{Results}

5.1.1. Results of the Routine Core Analysis. In the routine core analysis, core samples were tested to determined properties such as porosity, permeability, and saturation percentage of each. Table 1 below shows the results of that analysis.

5.1.2. Results of Capillary Pressure Measurements. Samples tested ranged from $50 \mathrm{md}$ to $232 \mathrm{md}$ air permeability ( $K_{\text {air }}$ at ambient). At the maximum air-brine capillary pressure, the selected samples yielded immobile water saturation $\left(S_{\text {wir }}\right)$ values between 13 and 22 percent pore volume (\% PV) and immobile oil saturation $\left(S_{o r}\right)$ values between 24 and 34 percent pore volume (\% PV). For most samples the requested maximum air-brine/air-oil capillary pressure of $35 \mathrm{psi}$ was attained.

5.1.3. Results of the Relative Permeability. The results of relative permeability of the core samples were estimated
TABLE 5: Relative permeability of the core samples (air-brine) $)_{S_{\text {unmod }}}$.

\begin{tabular}{|c|c|c|c|c|c|}
\hline Core & $P($ psia $)$ & $S_{w}(\%)$ & $S_{w}{ }^{*}(\%)$ & $K_{r w}$ & $k_{r a}$ \\
\hline \multirow{6}{*}{102} & 1 & 98.39 & 98.01 & 0.92 & 0.00001562 \\
\hline & 2 & 90.90 & 88.74 & 0.62 & 0.00269151 \\
\hline & 5 & 80.06 & 75.34 & 0.32 & 0.02628030 \\
\hline & 8 & 62.72 & 53.91 & 0.08 & 0.15073456 \\
\hline & 15 & 43.22 & 29.79 & 0.01 & 0.44926750 \\
\hline & 35 & 19.13 & 0.00 & 0.00 & 1.00 \\
\hline \multirow{6}{*}{546} & 1 & 98.24 & 97.91 & 0.91893743 & 0.0000181 \\
\hline & 2 & 91.85 & 90.30 & 0.66501503 & 0.0017346 \\
\hline & 5 & 80.02 & 76.24 & 0.33778045 & 0.0236519 \\
\hline & 8 & 63.19 & 56.21 & 0.09983124 & 0.1311665 \\
\hline & 15 & 41.77 & 30.74 & 0.00892358 & 0.4344419 \\
\hline & 35 & 15.93 & 0.00 & 0.00 & 1.00 \\
\hline \multirow{6}{*}{84} & 1 & 98.25 & 97.99 & 0.92195527 & 0.0000161 \\
\hline & 2 & 91.19 & 89.85 & 0.65184567 & 0.0019831 \\
\hline & 5 & 82.06 & 79.34 & 0.39628681 & 0.0158108 \\
\hline & 8 & 65.71 & 60.51 & 0.13407959 & 0.0988340 \\
\hline & 15 & 42.54 & 33.82 & 0.01308391 & 0.3878712 \\
\hline & 35 & 13.17 & 0.00 & 0.00 & 1.00 \\
\hline \multirow{6}{*}{ X } & 1 & 99.05 & 98.80 & 0.95294951 & 0.0000034 \\
\hline & 2 & 91.94 & 89.82 & 0.65087734 & 0.0020024 \\
\hline & 5 & 82.61 & 78.04 & 0.37098481 & 0.0188448 \\
\hline & 8 & 67.19 & 58.58 & 0.1177827 & 0.1126671 \\
\hline & 15 & 48.77 & 35.33 & 0.01557909 & 0.3660276 \\
\hline & 35 & 20.79 & 0.00 & 0.00 & 1.00 \\
\hline
\end{tabular}

$\left(S_{w}{ }^{*}\right.$ is the brine effective saturation).

assuming that the Brooks and Corey formula prescribe their relationships (7); the results are presented in the tables.

\subsection{Discussion of Results}

5.2.1. Wettability. The tested samples have porosities ranging from $23 \%$ to $33 \%$, with absolute air permeability of 50 to $233 \mathrm{md}$ and of grain density between $2.64 \mathrm{~g} / \mathrm{cc}$ and $2.69 \mathrm{~g} / \mathrm{cc}$. The routine core analysis data are good lithology indicators. With these, the lithology of the samples indicates that rock samples are quartz and carbonates minerals. Most common aquifer materials such as quartz, carbonates, and sulfates are strongly water-wet and since the tested samples are of quartz and carbonates materials; it was therefore assumed that the samples were initially water-wet.

Surfactants are surface active agents that can be used to alter the wettability of porous rocks. There are numerous methodologies and practices for studying and measuring wettability and its modification. The interactions of surfactants with reservoir materials to alter wettability are highly dependent upon the pore surface composition and pore structure as well as the characteristics of the surfactants. Wettability alteration of porous rock from surfactants can affect drilling, well completion, well stimulation, secondary or tertiary oil production, and environmental cleanup. In this 
work, the wettability of the core samples was altered to oil-wet using a surfactant.

5.2.2. Capillary Pressure. From the capillary pressure curves of the air-brine system, the wetting phase (brine) irreducible saturation ranged from 13 to $21 \%$ while that of the airoil system (oil) ranged from 25 to $34 \%$. The irreducible saturation of the wetting phase $\left(S_{\text {wir }}\right)$ before wettability alteration (air/brine system for water wet sample) is smaller than the irreducible saturation of the wetting phase $\left(S_{\text {or }}\right)$ after the wettability of the samples were changed to oil-wet (air-oil system) as shown in Figures 13 and 14. This is as a result of fractional wettability alteration of the core samples. Figures 11(a) and 11(b) show how the wettability of the core sample was changed by smearing paint on some surface faces of the cores. The saturation history of the core samples before and after wettability alteration also differs. It can be seen from Tables 2 and 3 that for an air-brine system; the nonwetting phase (air) easily displaces the wetting phase, while for an air-oil system, the displacement of the wetting phase (oil) is lower. This is as a result of fractional wettability alteration of the porous rock.

5.2.3. Relative Permeability. Tables 4 and 5 present the results of the relative permeability of the core samples for air-brine system and air-oil systems. From these tables and Figures 15(a)-15(d), we see that the relative permeabilities of the wetting phase for an air-brine system are lower than the relative permeabilities of the wetting phase for an air-oil system, while it is the opposite for their nonwetting phase relative permeabilities. This shows that altering the wettability of the core samples from water-wet to oil-wet increases the relative permeability of the wetting phase. This shows that oil recovery can be improved using this method.

\section{Conclusion}

This study has shown how wettability alteration of an initially water-wet reservoir rock to oil-wet reservoir rock affects the properties that govern multiphase flow in porous media, that is, capillary pressure, relative permeability, and irreducible saturation. Initial water-wet reservoir core samples with porosities of $23 \%$ to $33 \%$, absolute air permeability of 50 to $233 \mathrm{md}$, and initial saturation (brine) of $63 \%$ to $87 \%$ were first tested as water wet samples under air-brine system. This yielded an irreducible wetting phase saturation of $19 \%$ to $21 \%$. The samples were later tested after modifying their wettability to oil-wet using a surfactant; and a wetting phase irreducible saturation (oil) of $25 \%$ to $34 \%$ was obtained. From the results of these experiments, changing the wettability of the tested samples to oil-wet using a surfactant enables us to improve the recovery possibility of the wetting phase (oil).

\section{Nomenclature}

$A_{1}$ : Area under the oil-displacing brine curve

$A_{2}$ : Area under the brine-displacing oil curve

I: Amott wettability index

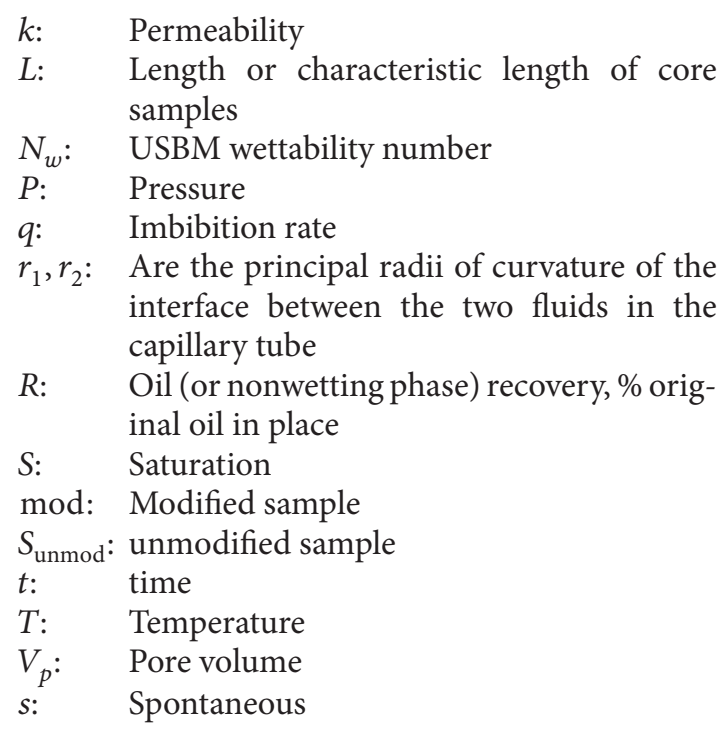

\section{Subscripts}

a: $\quad$ Aging

A: Advancing

AH: Amott-Harvey

c: Critical

$c$ : Capillary or characteristic

d: Dynamic

D: Dimensionless

E: Equilibrium

$f: \quad$ Flooding

$g:$ Gas

$i$ : Initial

im: Imbibition

$o: \quad$ Oil

or: Residual oil

ps: Pseudo

$r_{g}: \quad$ Gas relative permeability

$R: \quad$ Relative

sww: Strongly water-wet

$w$ : Water

Greek

$\Delta:$ Difference

$\theta$ : Contact angle

$\mu$ : Viscosity

$\Sigma$ : Area under capillary pressure curve

$\sigma$ : Interfacial tension, IFT

$\phi$ : Porosity.

\section{Conflict of Interests}

The authors declare that there is no conflict of interests regarding the publication of this paper.

\section{References}

[1] F. F. Craig, The Reservoir Engineering Aspects of Waterflooding, vol. 3 of SPE Monograph, Richardson, Tex, USA, 1971. 
[2] N. R. Morrow and J. C. Melrose, "Application of capillary pressure measurements to the determination of connate water saturation," in Interfacial Phenomena in Petroleum Recovery, N. R. Morrow, Ed., pp. 257-287, Marcel Dekker, New York, NY, USA, 1991.

[3] A. W. Adamson, Physical Chemistry of Surfaces, John Wiley \& Sons, 6th edition, 1990.

[4] W. G. Anderson, "Wettability literature survey-part 1: rock/oil/brine interactions and the effects of core handling on wettability," Journal of Petroleum Technology, vol. 38, no. 11, pp. 1125-1144, 1986.

[5] N. R. Morrow, "Wettability and its effect on oil recovery," Journal of Petroleum Technology, vol. 42, no. 12, pp. 1476-1484, 1990.

[6] A. Graue, E. Aspenes, T. Bognø, R. W. Moe, and J. Ramsdal, "Alteration of wettability and wettability heterogeneity," Journal of Petroleum Science and Engineering, vol. 33, no. 1-3, pp. 3-17, 2002.

[7] M. N. Derahman and M. K. Zahoor, "Prediction and estimation of capillary pressure for wettability and wettability variations within reservoir," in Proceedings of the 13th Abu Dhabi International Petroleum Exhibition and Conference (ADIPEC '08), pp. 591-609, November 2008.

[8] L. W. Lake, Enhanced Oil Recovery, Prentice-Hall, Englewood Cliffs NJ, USA, 1989.

[9] S. K. Masalmeh, X. D. Jing, W. van Vark, H. van der Weerd, S. Christiansen, and J. van Dorp, "Impact of SCAL on carbonate reservoirs: how capillary forces can affect field performance predictions," in Proceedings of the International Symposium of the Society of Core Analysts (SCA '03), SCA 2003-36, Pau, France, October 2003.

[10] D. W. Ruth and Z. A. Chen, "Measurement and interpretation of centrifuge capillary pressure curves - the SCA survey data," The Log Analyst, vol. 36, no. 5, pp. 21-33, 1995.

[11] G. R. Jerauld and S. J. Salter, "The effect of pore-structure on hysteresis in relative permeability and capillary pressure: porelevel modeling," Transport in Porous Media, vol. 5, no. 2, pp.103151, 1990.

[12] M. Honarpur, L. Koederitz, and A. H. Harvey, Relative Permeability of Petroleum Reservoirs, CRC Press, 1986.

[13] P. H. Valvatne and M. J. Blunt, "Predictive pore-scale modeling of two-phase flow in mixed wet media," Water Resources Research, vol. 40, no. 7, Article ID W07406, 2004.

[14] S. AL-Sayari and M. Blunt, "The Effect of wettability on relative permeability, capillary pressure, electrical resistivity and NMR," in Benchmark Experiments on Multiphase Flow, Imperial College of London, 2012.

[15] M. T. Al-Garni and B. D. Al-Anazi, "Investigation of wettability effects on capillary pressure, and irreducible saturation for Saudi crude oils, using rock centrifuge," Oil and Gas Business, 2008.

[16] D. P. Green, J. R. Dick, M. McAloon, P. F. D. J. Cano-Barrita, J. Burger, and B. Balcom, "Oil/water imbibition and drainage capillary pressure determined by MRI on a wide sampling of rocks," in Proceedings of the 22nd International Symposium of the Society of Core Analysts, Abu Dhabi, UAE, 2008.

[17] J. Chen, G. J. Hirasaki, and M. Flaum, "NMR wettability indices: effect of OBM on wettability and NMR responses," Journal of Petroleum Science and Engineering, vol. 52, no. 1-4, pp. 161-171, 2006.

[18] D. M. O'Carroll, L. M. Abriola, C. A. Polityka, S. A. Bradford, and A. H. Demond, "Prediction of two-phase capillary pressure-saturation relationships in fractional wettability systems," Journal of Contaminant Hydrology, vol. 77, no. 4, pp. 247270, 2005.

[19] S. Békri, C. Nardi, and O. Vizika, "Effect of wettability on the petrophysical parameters of vuggy carbonates: network modeling investigation," in Proceedings of the International Symposium of the Society of Core Analysts held in Abu Dhabi, UAE, October 2004.

[20] K. Li and A. Firoozabadi, "Experimental study of wettability alteration to preferential gas-wetting in porous media and its effects," SPE Reservoir Evaluation \& Engineering, vol. 3, no. 2, pp. 139-149, 2000.

[21] M.-H. Hui and M. J. Blunt, "Effects of wettability on three-phase flow in porous media," Journal of Physical Chemistry B, vol. 104, no. 16, pp. 3833-3845, 2000. 

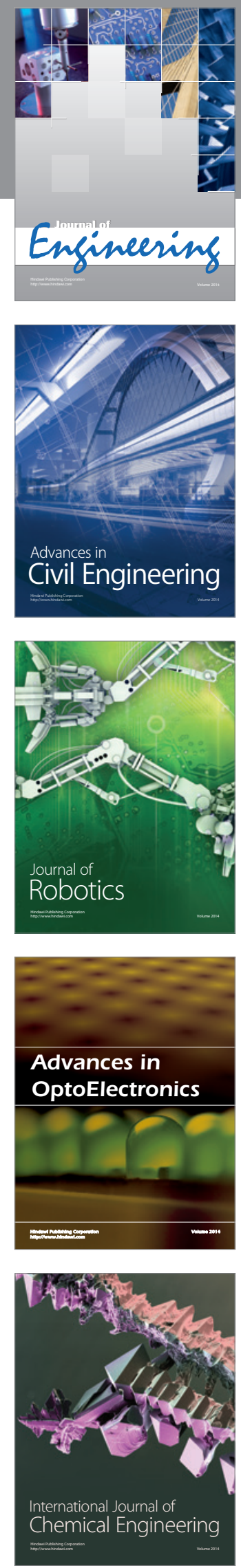

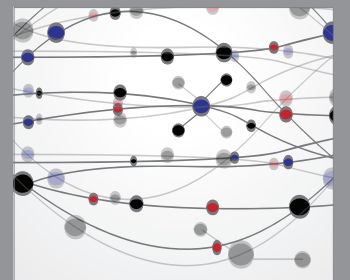

The Scientific World Journal
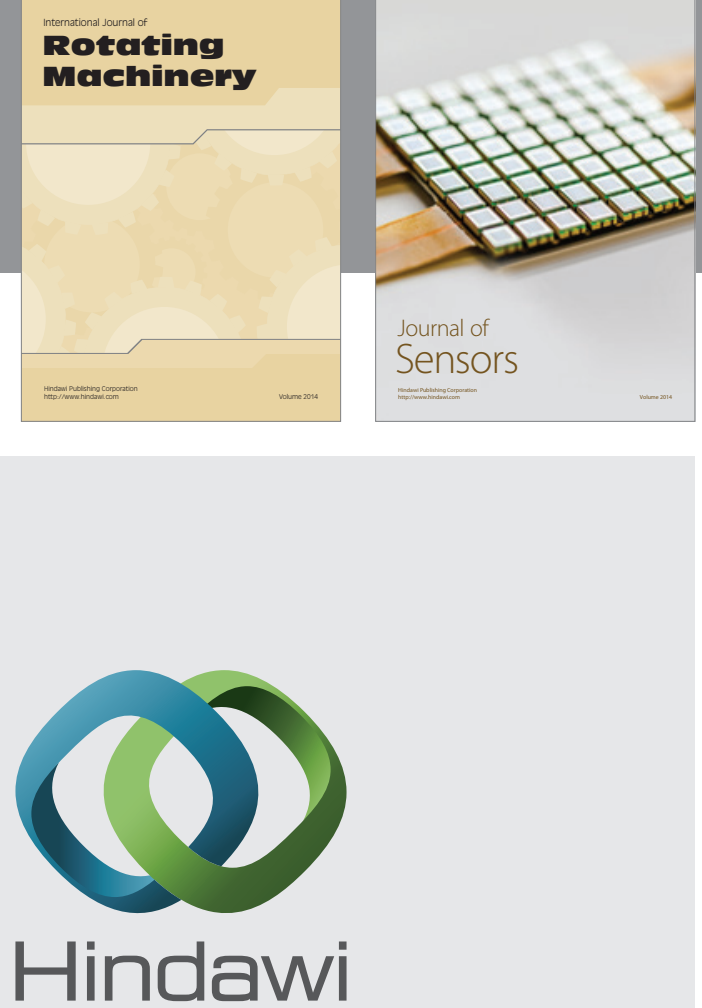

Submit your manuscripts at http://www.hindawi.com
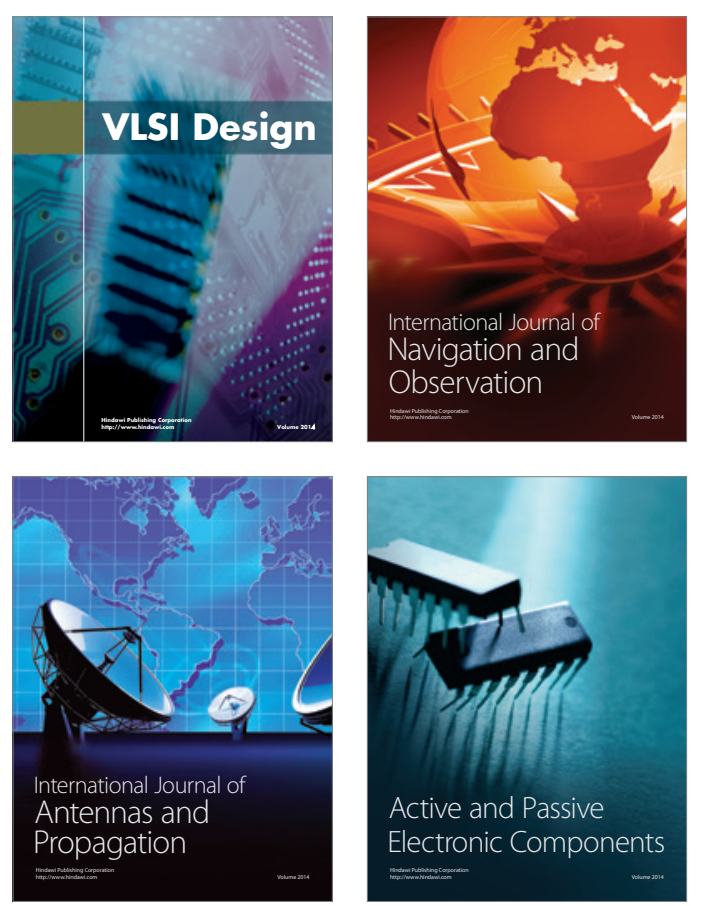
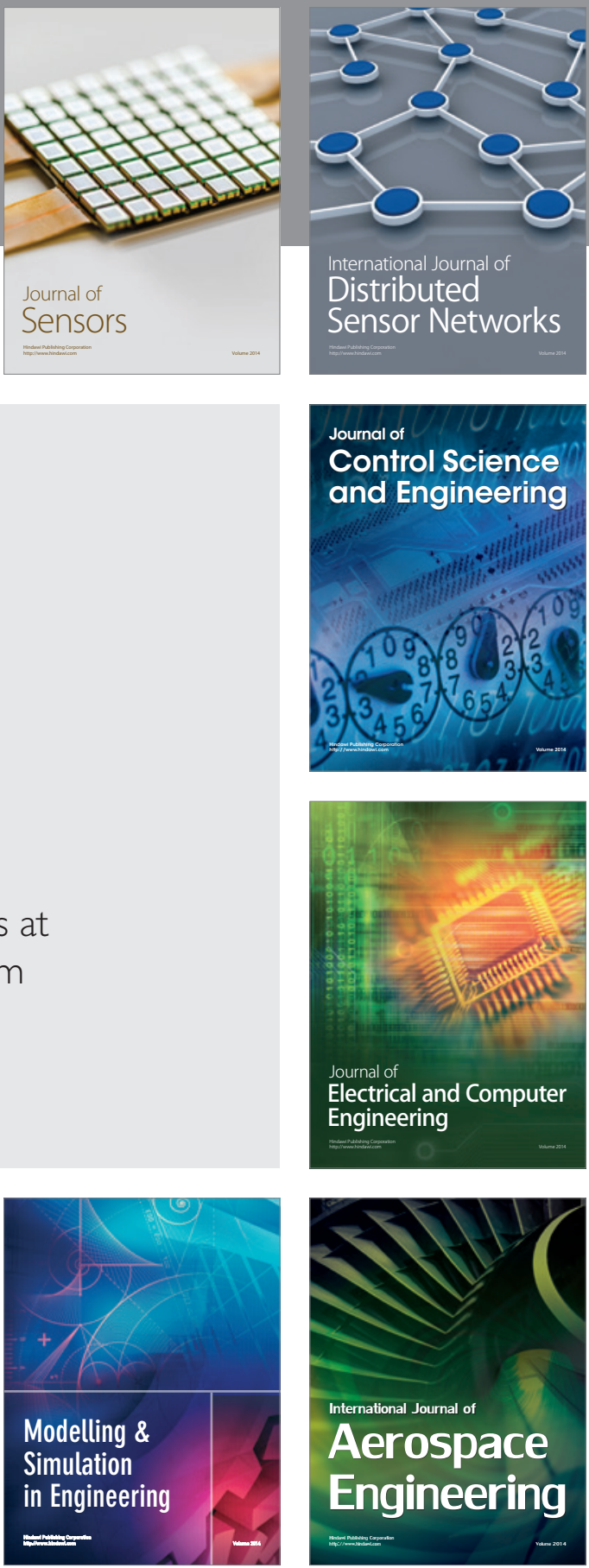

Journal of

Control Science

and Engineering
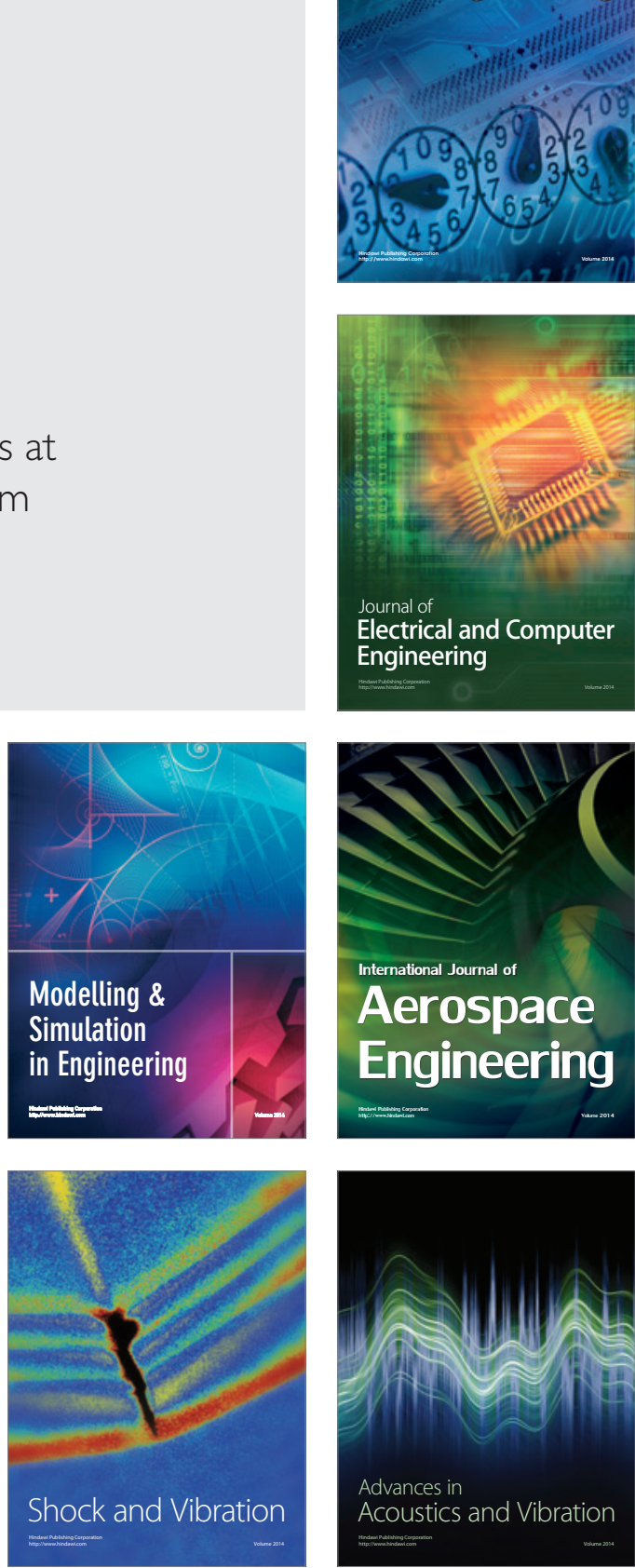